\section{Evergreen Brick Works:
An Innovation and Sustainability Case Study \\ Evergreen Brick Works:
An Innovation and Sustainability Case Study Seana Irvine}

\author{
"We can rethink and rebuild many ... sectors of society on a" \\ profoundly new, open, networked model. Indeed, for the first \\ time in history, people everywhere can participate fully in \\ achieving this new future.
}

Don Tapscott

Author, Speaker, and Advisor on Media, Technology, and Innovation

\begin{abstract}
Technology is rapidly being deployed to advance social innovation that creates lasting change. This case study of Evergreen Brick Works explores how Evergreen is leveraging the power of its unique new campus as a showcase for advancing sustainability-related behavioural change along with new and emerging state-of-the-art technologies to advance its mission. The ultimate success of these technologies will be in their ability to engage larger numbers and greater diversity among participants, and in their ability to translate new insights into on-the-ground change in their communities. The article also identifies that the need for an organizational network mindset is as important as the technologies to achieve these changes.
\end{abstract}

\section{Introduction}

Evergreen (evergreen.ca) was founded in 1990 with a mission to inspire action to green cities. When I first started working at Evergreen 15 years ago, we had one Internet connection. Wires and cables ran out the windows to connect floors and you had to call out, "Anybody online?" before trying to go online yourself, lest you boot somebody off - which happened often.

Times have changed. Technology has changed every aspect of our world, shrinking the distance between borders, the ways that we work and, perhaps most significantly, how we communicate with one another. As Evergreen's Chief Operating Officer, I have witnessed first hand how Evergreen has been swept along with these rapid advances in technology and our experience, in many ways, mirrors these broader trends. Information and communication technology (ICT) has changed how we organize ourselves to do our work and the myriad ways we connect with a diverse and growing network of stakeholders across the country involved in the urban sustainability movement.
This article explores how ICT is helping Evergreen mature from a fledgling grassroots organization to among Canada's largest environmental not-for-profit organizations, and the ways that information technology at Evergreen Brick Works (ebw.evergreen.ca) - our flagship site is helping enhance communication, education and action towards social change and the creation of greener, more resilient cities.

\section{About Evergreen}

Over $80 \%$ of Canadians and half of the world's seven billion people live in urban centres (Statistics Canada, 2007; tinyurl.com/7bh64jy). While cities are social and economic hubs and generators of innovation and creativity, they also consume a disproportionate share of the world's natural resources, and their design disconnects their inhabitants from nature. It is clear that the planet's climate is actually changing as a direct result of human activity - much of it linked to urbanization - and this fact is creating unprecedented and dangerous risks. On a global scale, the earth's air and water are increasingly contaminated, more people are living in urban 


\section{Evergreen Brick Works: An Innovation and Sustainability Case Study}

\section{Seana Irvine}

poverty than ever before, and patterns of urbanization are accelerating the wholesale destruction of essential natural areas and agricultural land - and with that, the loss of vital habitat and biodiversity.

At the core of Evergreen's work is the belief that involving people directly in the process of restoring the natural health of their communities positively affects the attitudes and behaviours that lie at the core of the sustainable city. We believe that pressing urban environmental issues can be solved by bringing diverse groups of people together, inspiring them with possibilities and, identifying solutions, and taking action. This approach has helped us engage over one million Canadians from all walks of life in the active transformation of thousands of derelict asphalt and turf grass public parks and school grounds into vibrant natural areas and dynamic, healthy community spaces.

\section{Evergreen Brick Works}

For over 100 years, the Don Valley Brick Works manufactured bricks that built landmark buildings across Canada and that helped shape the skyline of Toronto. Nestled among Toronto's ravine network, the factory produced over 43 million bricks a year at its peak. When it closed down in the late 1980s, all that was left of the Don Valley Brick Works was 42 acres of damaged ecosystem, 14 crumbling industrial heritage buildings, and a lot of contaminated soil.

In 2002, Evergreen began its revitalization of the Brick Works. Eight years later, Evergreen officially opened "Evergreen Brick Works" as Canada's first large-scale community environmental centre and a venue for celebrating innovation in urban greening. Evergreen Brick Works is a vibrant public space where visitors can engage in a broad suite of hands-on environmental programs and it is a place to demonstrate and share best practices for restoring the environment, creating healthier communities, and strengthening the emerging green economy. To transform the site, Evergreen embedded the values of collaboration, environmental sustainability, economic viability, and change and adaptation into our design process.

\section{Collaboration}

From the outset, the intent was to create a dynamic and interactive space where environmental issues were not marginalized as a discreet set of considerations, but rather, to create a physical space and visitor experience that explores and showcases how nature is central to all aspects of urban life. This holistic approach requires multiple collaborations with complementary organizations, including community service, environmental, arts and youth organizations, social innovators, all levels of government, academia, and environmental innovators. We consulted widely with partner organizations, site stakeholders, and the community-at-large as we undertook the planning and design.

Given the complexities of redeveloping the site (brownfield, heritage designated, and located in a floodplain, among other realities), our green design ambitions, and a tight budget, problem solving was a daily occurrence. Evergreen worked hard to facilitate solutions among multiple partners and stakeholder audiences while not losing site of the vision.

\section{Environmental design and sustainability}

To demonstrate leadership and serve as an international showcase for green design and urban innovation, Evergreen Brick Works has been redeveloped to the highest standards of green design, including a LEED platinum building (tinyurl.com/2xqdgy), and extensive resource conservation features employed throughout.

\section{Social entreprise}

Evergreen Brick Works also functions as a social entreprise, with revenue generated through property management, third-party events, parking, and our garden centre covering 100 percent of operating costs. This objective is central to the long-term financial viability of the site. It also gives Evergreen access to new audiences and new engagement strategies, and thus opportunities to have a greater impact.

\section{Change and adaptation}

The campus-like nature of Evergreen Brick Works, its physical and economic relationship to the city, and the deep social and cultural connections many had to it, made its redevelopment a microcosm of city planning. The recognition that the site itself had evolved constantly over time in response to changing environmental, economic, and social conditions, was central to our approach. Spaces were designed with a light touch for maximum flexibility and multi-purposing.

\section{Walking the Talk}

A commitment to environmental best practices, to creativity and innovation, to deep collaboration, and the recognition that change and evolution are constants in 


\section{Evergreen Brick Works: An Innovation and Sustainability Case Study}

\section{Seana Irvine}

complex environments, now informs our approach to programming and the visitor experience. And, it is this same approach and set of values that we are now using as we begin to advance the implementation of new ICT tools and systems. These ICT tools are enabling participants to contribute their ideas and feedback in real time both onsite and remotely. With an eye to continuing to advance the highest standards in green design and environmental sustainability, ICT will support operational efficiencies that conserve natural (and thus financial) resources while allowing for transparency in how the site is performing. And, most critically to Evergreen's mission, ICT tools are helping Evergreen share ideas and innovations from among an increasingly diverse and growing network of collaborators, helping us connect and inspire others involved in advancing social change through greening our urban environments.

In 2011, our ICT ambitions took a great leap forward with a generous in-kind investment in our IT capabilities from Cisco Canada (cisco.com). The following presents a summary of some of the key information and communication technologies that Evergreen is pursuing as intentional strategies for inspiring social change, from high-tech solutions such as integrated building control systems, to user driven and comparatively low-tech solutions, such as uploading images to websites. Further examples include:

- digital signage supporting programming, way-finding, and displaying building performance

- online and hand-held tools for education, interpretation, and civic engagement

- enhanced connectivity, such as video conferencing and site-wide wireless

- increased security of IT systems and data

- sophisticated analytic, diagnostic, and management tools to help Evergreen maintain growing IT needs with a small and efficient IT team

Operating a green campus: Resource conservation and operating efficiency

A digital lighting control system with daylight and occupancy sensors reduces unnecessary lighting by automatically adjusting brightness in hundreds of indoor and outdoor fixtures. This system allows for $57 \%$ energy savings compared to standard construction. Integrated building control systems help conserve energy associated with operating the Evergreen Brick Works campus. We are working with Cisco Canada (cisco.com) and Fifth Light Technology (fifthlight.com) to install a combination of centralized and distributed sensors and controls for monitoring and managing energy use. Through one digital interface, the building manager can control energy use, both on-site or remotely, for lighting, fans, heating and ventilation, and mechanical systems.

Promoting civic engagement through data visualization We are working with a diverse group of partners - from governments and academics to non-governmental organizations and technology service providers - using information technology and data visualization to promote civic engagement in improving the health of our cities. This initiative is being developed to operate on a number of scales. We are installing sensing and monitoring systems on site that allow us to monitor and measure how the strategies we implemented to reduce resource consumption in the built environment and heal the natural landscape are working. Using realtime monitoring sensors and manual monitoring through citizen science (tinyurl.com/c9gkxv), we are measuring energy and water consumption, waste generation, and transportation-related impacts, temperature, rainfall, solar radiation, wind, and flora and fauna around the site.

Our web-enabled dashboard will distill and provide easy access to this information for public engagement and education. The dashboard will communicate how the site is performing, what we are learning as we go, and provide examples for what consumers can do to green their homes. On the macro scale, we are beginning to look at how to apply analytics and data visualization to help understand the complex systems dynamics of cities and render them more accessible to the general public.

\section{Education and interpretation}

Evergreen's website features an interactive green design exhibit (ebw.evergreen.ca/about/green-design) with separate pages that profile five basic principles of city building: adaptive reuse, brownfield remediation, building envelope, heating and cooling, and resource conservation. Web visitors can scroll through each page, clicking on numerous highlighted features, such as water-pervious paving or greenways on the brownfield remediation page. Each link profiles the actions Evergreen has taken to minimize the ecological foot- 


\section{Evergreen Brick Works: An Innovation and Sustainability Case Study}

Seana Irvine

print of its construction and operations. This technology allows Evergreen to share its green design strategies for visitors remotely.

We also created an interactive map of Canada profiling school and community greening projects that Evergreen has directly supported. Staff plotted every Evergreen-related greening initiative across Canada (in all provinces and in two of the territories). As conveyed to our community partners:

"In the face of today's environmental concerns - from polluted air and water to species loss and climate change - it would be understandable if people felt a little overwhelmed. But this map of Canada (tinyurl.com/coqgw8b) tells a different story. It shows how your own greening project connects with hundreds of others like it across Canada. Collectively, you are ensuring that all Canadians stay connected with nature, one green space at a time."

\section{Participatory monitoring strategies}

Ten photo-monitoring stations across the site invite visitors to take photos from the exact location, helping Evergreen communicate through images, the story of ecological restoration over time at Evergreen Brick Works. For example, stations face onto a stormwater wetland pond, several large-scale garden beds, and a ravine slope that was stabilized and replanted through the construction process. Each station includes instructions for uploading their photos to Evergreen's Flickr account (tinyurl.com/c9ubgjx). This strategy recognizes that the site is always changing, through the seasons and year-over-year, and it engages visitors in documenting its ecological health.

\section{User apps for navigating cities}

In launching our inaugural large-scale exhibit, MOVE: The Transportation Expo (ebw.evergreen.ca/move/), Evergreen, and our partner, the Institute without Boundaries of George Brown College (institutewithoutboundaries.com), led a design charette that challenged leaders from government, industry, and academia to find creative solutions to regional transportation challenges by drawing on global best practices. The charette process launched 10 multi-stakeholder groups to advance key innovations with the results providing original content that will be featured in the exhibits.

One design team was asked to design a street grid system that would involve a dynamic web of multi-functional and "flexible" streets - meeting a variety of needs at different times of the day and for different times of the year. The team considered a host of mobility options for Toronto's densely populated urban core, focusing on commuters, residents, businesses, and tourists, and using a holistic approach to mobility and the complete-streets concept. A mobile application was developed that would enable users to make efficient transportation decisions based on real-time data and enhance their experience by providing incentives (e.g., discounts, reward points) for making more environmentally-friendly transportation choices.

\section{Enhancing customer service}

Because of the existing configuration of the industrial heritage buildings, the Welcome Desk for Evergreen Brick Works is not the first door that most visitors walk through. Rather, the most prominent doors are the entrance to a café and garden centre. This makes it difficult for visitors trying to find their way and for the staff running these spaces, who can become inundated with general inquiries. To assist visitors in navigating the multiple entry points on the site, we are setting up a virtual concierge. This technology will allow visitors to press an interactive screen to reach a person in addition to providing general information, wayfinding, and other site details. Cameras will be stationed at staff desks so that visitors will be able to (virtually) reach a real person.

\section{Social media}

Blogging, Twitter, and Facebook have all helped exponentially increase Evergreen's ability to communicate with groups and individuals. In two years, we have attracted approximately 10,000 new followers including access into new demographic and geographic areas. A recent partner event hosted at Evergreen Brick Works attracted over 3,000 visits - 2,000 more than anticipated - thanks to the power of social media. Specific campaigns to generate additional momentum are also organized. For example, to support MOVE: The Transportation Expo, Evergreen launched "Month in a Car" in which our candidate will spend one month (the total average time Torontonians commute to and from work every year) in a car, making media appearances, interacting with the public through social media, and interviewing industry experts to create a 12-part webisode series.

\section{Social entreprise}

The IT enhancements will also support our objective of operating Evergreen Brick Works as a financially selfsustaining entreprise by helping to strengthen earned revenue streams and sponsorship opportunities. ICT 


\section{Evergreen Brick Works: An Innovation and Sustainability Case Study}

\section{Seana Irvine}

tools will improve the marketability of the site for thirdparty event clients, prospective tenants, and sponsors through high-bandwidth wireless access, rental of video conferencing units, and the ability to support larger conferences. Digital signage will offer new sponsorrecognition opportunities, and enhanced connectivity packages will provide new offerings to prospective and existing tenants.

\section{Conclusion}

These are still early days for the implementation of new ICT at Evergreen Brick Works and there is an ever-expanding array of new opportunities for reaching and engaging growing numbers of Canadians. Assessing these new ICT opportunities within a similar framework to the one used in the design and transformation of Evergreen Brick Works holds promise for increasing the effectiveness of new ICT initiatives. Though the substance is different, the context is similar.

Beyond Evergreen Brick Works and the emerging ICT, we also believe that the "network mindset", that is, a "stance toward leadership that prioritizes openness, transparency, making connections and sharing control" (Scearce, 2011; tinyurl.com/6m2zsot) contributes to the effectiveness of these technologies. Positioning our work within the understanding and acknowledgement that we operate in an interdependent world requires coordination and collaboration. Keeping sight of this will help Evergreen learn, grow, and evolve these new technologies in the ongoing effort to create a lasting legacy that helps change our relationships with each other and the natural environment.

\section{About the Author}

Seana Irvine is Evergreen's Chief Operating Officer, overseeing the management and coordination of Evergreen's 100+ staff, driving key strategic directions, and leading and facilitating operational plans and processes. Seana was an original team member in the development and start-up of Evergreen Brick Works, helping drive program strategies in tandem with the design process. She has a Master's degree in Environmental Studies (Planning) and serves on the boards of several not-for-profit organizations.

Citation: Irvine, S. 2012. Evergreen Brick Works: An Innovation and Sustainability Case Study. Technology Innovation Management Review. July 2012: 21-25. 